\title{
Correction to: Sleep Neurology's Toolkit at the Crossroads: Challenges and Opportunities in Neurotherapeutics Lost and Found in Translation
}

\author{
Erik K. St Louis ${ }^{1,2} \cdot$ Aleksandar Videnovic $^{3}$
}

Published online: 30 April 2021

(c) The American Society for Experimental NeuroTherapeutics, Inc. 2021, corrected publication, 2021

Correction to: Neurotherapeutics (2021)

https://doi.org/10.1007/s13311-021-01032-7

This erratum is to correct the spelling of the authors name.

It should be spelled as Erik K. St Louis.

The original article has been corrected.
Publisher's Note Springer Nature remains neutral with regard to jurisdictional claims in published maps and institutional affiliations.

The original article can be found online at https://doi.org/10.1007/ s13311-021-01032-7.

Erik K. St Louis

StLouis.Erik@mayo.edu

1 Mayo Center for Sleep Medicine, Division of Pulmonary and Critical Care Medicine, Departments of Neurology and Medicine, Mayo Clinic College of Medicine and Science, Rochester, MN, USA

2 Department of Clinical and Translational Research, Mayo Clinic Health System Southwest Wisconsin, La Crosse, WI, USA

3 Divisions of Sleep Medicine and Movement Disorders, Department of Neurology, Massachusetts General Hospital, Harvard University, Boston, MA, USA 